\title{
NOTE
}

\section{Isolation and Identification of 4, 4'-Diapolycopene- 4,4'-dioic Acid Produced by Bacillus firmus GB1 and its Singlet Oxygen Quenching Activity}

\author{
Ayako Osawa ${ }^{1}, K^{2}$ anoko Iki', Gerhard Sandmann ${ }^{2}$ and Kazutoshi Shindo ${ }^{1 *}$ \\ ${ }^{1}$ Department of Food and Nutrition, Japan Women's University, 2-8-1, Mejirodai, Bunkyo-ku, Tokyo 112-8681, Japan \\ ${ }^{2}$ Biosynthesis Group, Institute of Molecular Biosciences, Goethe University, 60054 Frankfurt/Main, Germany
}

\begin{abstract}
We succeeded in purifying the carotenoid produced by Bacillus firmus GB1 using chromatography on polystyrenic synthetic adsorbents, and identified it as $4, \mathbf{4}^{\prime}$ '-diapolycopene-4,4'-dioic acid by HRESI-MS and NMR analyses of it and its dimethylester. In addition, we clarified the singlet oxygen $\left({ }^{1} \mathrm{O}_{2}\right)$ quenching activities of 4,4'-diapolycopene-4,4'-dioic acid and its methyl esters (mono and dimethyl ester). Their IC $_{50}$ values were $5.8 \mu \mathrm{M}, 6.0 \mu \mathrm{M}$, and $6.2 \mu \mathrm{M}$, respectively. To our knowledge, this is the first report concerning the isolation and antioxidative activity of 4,4'-diapolycopene-4,4'-dioic acid, a product of the $\mathrm{C} 30$ carotenoid biosynthesis pathway.
\end{abstract}

Key words: 4,4'-diapolycopene-4,4'-dioic acid, Bacillus firmus GB1, polystyrenic synthetic adsorbent, ${ }^{1} \mathrm{O}_{2}$ quenching activity

\section{INTRODUCTION}

Carotenoids are terpenoids possessing a chain of 30, 40 or 50 carbons. More than 750 carotenoids with different molecular structures have been isolated from natural sources ${ }^{1)}$. Evaluating the pharmaceutical potential of various carotenoid pigments could be an exciting field of medical research; however, the carotenoid species so far studied for medical research have been restricted to a small number, including dicyclic carotenoids, such as $\beta$-carotene, $\alpha$-carotene, $\beta$-cryptoxanthin, zeaxanthin, lutein, canthaxanthin, astaxanthin and fucoxanthin, and an acyclic carotenoid, lycopene ${ }^{2-5)}$. Thus, we have started to screen for novel or rare antioxidative carotenoids from pigmented rare bacteria.

Bacillus firmus GB1 is a microorganism isolated from the human ileum and identified to be a novel Bacillus species by $16 \mathrm{~S}$ rRNA analyses ${ }^{6)}$. B. firmus GB1 produce a deep pink pigment, which was speculated to be a C30 carotenoid due to its characteristic UV-Vis absorption and the biosynthetic genes found in $B$. firmus $\mathrm{GB}^{7}{ }^{7}$, however the isolation and detailed structural analyses by nuclear magnetic resonance (NMR) of this pigment were not successful in previous studies due to its inconsistent retention behav- iors on silica gel and ODS HPLC. In this study, it was found that this pigment gave a sharp elution peak on polystyrenic synthetic adsorbents (HP20SS and CHP20/C10) and it could be purified it through an isolation scheme including these resins. It was also identified as 4,4'-diapolycopene dioic acid by high resolution electrospray ionization mass spectrometry (HRESI-MS) and NMR analyses of it and its dimethyl ester. Although the production of 4,4'-diapolycopene- $4,4^{\prime}$-dioic acid by bacteria has been reported in previous studies ${ }^{8)}, 4,4$ '-diapolycopene-4,4'-dioic acid itself has not been isolated before as a free acid, therefore, this is the first report on the isolation of 4,4 '-diapolycopene-4,4'-dioic acid without modification from the producing bacteria. In addition, we also report the complete ${ }^{1} \mathrm{H}$ and ${ }^{13} \mathrm{C}$ NMR assignments of 4,4'-diapolycopene-4,4'-dioic acid and its methyl esters (monomethyl ester and dimethyl ester) for the first time.

We investigated the singlet oxygen $\left({ }^{1} \mathrm{O}_{2}\right)$ quenching activities of 4,4'-diapolycopene-4,4'-dioic acid and its methyl esters (monomethyl ester and dimethyl ester), since potent ${ }^{1} \mathrm{O}_{2}$ quenching activities were reported on some carotenoids $^{9,10)}$. The tested carotenoids showed potent antioxidative activities.

\footnotetext{
*Correspondence to: Kazutoshi Shindo, Department of Food and Nutrition, Japan Women's University, 2-8-1 Mejirodai, Bunkyo-ku, Tokyo 112-8681, Japan

E-mail: kshindo@fc.jwu.ac.jp

Accepted June 17, 2013 (received for review March 22, 2013)

Journal of Oleo Science ISSN 1345-8957 print / ISSN 1347-3352 online

http://www.jstage.jst.go.jp/browse/jos/ http://mc.manusriptcentral.com/jjocs
} 


\section{A. Osawa, K. Iki, G. Sandmann et al.}

\section{EXPERIMENTAL}

\subsection{Cultivation}

The $-80^{\circ} \mathrm{C}$ frozen culture of $B$. firmus $\mathrm{GB} 1(1 \mathrm{~mL})$ was inoculated into $200 \mathrm{~mL}$ LB medium(tryptone $10.0 \mathrm{~g}$, yeast extract $5.0 \mathrm{~g}$, and $\mathrm{NaCl} 7.0 \mathrm{~g}$ in $1 \mathrm{~L}$ ) in a $500 \mathrm{~mL}$ Erlenmeyer flask and cultured at $30^{\circ} \mathrm{C}$ for $48 \mathrm{~h}$ on a rotary shaker $(150$ rpm). Each $2 \mathrm{~mL}$ of the seed culture was inoculated into $200 \mathrm{~mL}$ LB medium in a $500 \mathrm{~mL}$ Erlenmeyer flask and cultured at $30^{\circ} \mathrm{C}$ for $48 \mathrm{~h}$ on a rotary shaker (150 rpm). The $\mathrm{OD}_{490}$ was 9.3 after the $48 \mathrm{~h}$ cultivation.

\subsection{HPLC}

HPLC was carried out using a Hitachi L-7100 intelligent pump and L-7400 DAD detector. The maximum absorbance was measured in the range of $200-600 \mathrm{~nm}$.

\subsection{Spectroscopic analysis}

${ }^{1} \mathrm{H},{ }^{13} \mathrm{C}$, and $2 \mathrm{D}$ NMR spectra were measured with a Bruker AVANCE400. Chemical shifts were referenced to tetramethylsilane. Data processing was performed using Top Spin-NMR software(version 3.0) (Bruker BioSpin). HRESI-MS and high resolution atmospheric pressure chemical ionization mass spectrometer (HRAPCI-MS) was recorded with a JEOL JMS-T100LP mass spectrometer. UV-VIS spectra were recorded with a Hitachi U-3200.

\subsection{Isolation of $4,4^{\prime}$-diapolycopene-4,4'-dioic acid}

B. firmus GB1 cells from $10 \mathrm{~L}$ culture were collected by centrifugation at 13,000 g. After removing the supernatant, the deep pink pigment in the cells was extracted 6 times with $\mathrm{MeOH}(50 \mathrm{~mL})$ by sonication for $5 \mathrm{~min}$. The extracts were combined $(300 \mathrm{~mL})$ and added $n$-hexane $(300 \mathrm{~mL})$ to partition between $n$-hexane/MeOH. The MeOH (lower) layer was concentrated to a small volume, and partitioned between $t$-butyl methyl ether-MeOH (500 mL: $100 \mathrm{~mL}) / \mathrm{H}_{2} \mathrm{O}$ $(600 \mathrm{~mL}$ ) without adjusting the $\mathrm{pH}$. The $t$-butyl methyl ether-MeOH (upper) layer was evaporated to dryness to give a brown oil (474.2 mg). This oil was dissolved in $n$ hexane-EtOH (1: 3) $0.5 \mathrm{~mL}$ and applied to HP20SS (Mitsubishi Chemical Co.) column chromatography $[20 \times 300 \mathrm{~mm}$, solvent: $n$-hexane-EtOH (1:3) ], and developed with the same solvent.

The deep pink fraction was collected and concentrated to dryness to give a deep pink oil $(98.5 \mathrm{mg})$. This oil was subjected to preparative ODS HPLC (Develosil C30-UG-5, $10 \times 250 \mathrm{~mm}$, Nomura Chemical Co.) and developed at a flow rate of $3 \mathrm{~mL} / \mathrm{min}$ with solvent $\mathrm{A}[t$-butyl methyl ether$\mathrm{MeOH}(1: 9)]$ for $5 \mathrm{~min}$, then by linear gradient from solvent A to solvent $\mathrm{B}\left[t\right.$-butyl methyl ether-MeOH- $\mathrm{H}_{2} \mathrm{O}$ (70:26:4) ] for $6 \mathrm{~min}$, and finally with solvent B for $14 \mathrm{~min}$.

The deep pink peak (Rt 12-14 min) was collected and evaporated to dryness (31.2 mg), and further subjected to a preparative polystyrenic HPLC column (MCI gel CHP20/ C10, 4.6 × 250 mm; Mitsubishi Chemical Co.) and developed at a flow rate of $1 \mathrm{~mL} / \mathrm{min}$ with solvent $\mathrm{C}\left(\mathrm{CH}_{2} \mathrm{Cl}_{2}\right)$ for $5 \mathrm{~min}$, then by a linear gradient from solvent $\mathrm{C}$ to solvent $\mathrm{D}$ $\left[\mathrm{CH}_{2} \mathrm{Cl}_{2}-\mathrm{MeOH}(5: 1)\right]$ for $10 \mathrm{~min}$, and finally with solvent D for 15 min. The deep pink peak eluted at 15.8 min was collected and concentrated to give pure $4,4^{\prime}$-diapolycopene-4,4'-dioic acid.

\subsection{Methylation of 4,4'-diapolycopene dioic acid}

The $B$. firmus GB1 cells (17 L) were extracted with $\mathrm{MeOH}(360 \mathrm{~mL})$ and partitioned between $n$-hexane (360 $\mathrm{mL} / \mathrm{MeOH}$. The $\mathrm{MeOH}$ layer was concentrated to dryness $(1.62 \mathrm{~g})$, and re-dissolved in $20 \mathrm{~mL} \mathrm{CH}_{2} \mathrm{Cl}_{2}$. The diazomethane solution $\left(100 \mathrm{~mL} \mathrm{Et}_{2} \mathrm{O}\right.$ ) prepared by adding $5 \mathrm{~g}$ of 1-methyl-3-nitro-1-nitrosoguanidine (Tokyo Chemical Industry Co., Ltd.) to an $\mathrm{Et}_{2} \mathrm{O}(120 \mathrm{~mL}) / 3 \mathrm{~N} \mathrm{KOH}(50 \mathrm{~mL})$ bilayer, was added to the $\mathrm{CH}_{2} \mathrm{Cl}_{2}$ solution, and the solution was stirred for $10 \mathrm{~min}$ at room temperature under dark conditions. After removing the solvent in vacuo, the residue was dissolved in EtOAc $(500 \mathrm{~mL})$, and partitioned between EtOAc/ $\mathrm{H}_{2} \mathrm{O}(500 \mathrm{~mL})$ without adjusting the $\mathrm{pH}$. The EtOAc layer was concentrated to dryness $(842.6 \mathrm{mg}$ ), and applied to HW40 gel chromatography $(20 \times 40 \mathrm{~mm})$ with $\mathrm{CH}_{2} \mathrm{Cl}_{2}-\mathrm{MeOH}(1: 1)$. Two red fractions ffr. 8-13(A) and fr $15-17(B)\}$ were collected separately and concentrated to dryness (A: $215.1 \mathrm{mg}, \mathrm{B}: 153.1 \mathrm{mg}$ ). Fraction A was applied to silica gel (Silica Gel 60; Merck) column chromatography [20 × 160 mm, solvent: $n$-hexane-EtOAc (20:1)] and developed with $n$-hexane-EtOAc first with a 20:1 mixture (350 $\mathrm{mL})$ and then with a 10:1 mixture $(220 \mathrm{~mL})$. The red fraction eluted by $n$-hexane-EtOAc (10:1) was collected and concentrated to give pure $4,4^{\prime}$-diapolycopene-4,4'-dioic acid dimethyl ester $(2,2.6 \mathrm{mg})$. Fraction B was applied to silica gel column chromatography $[15 \times 120 \mathrm{~mm}$, solvent: $n$ hexane-EtOAc $(3: 1)]$ and developed with the same solvent. The red fraction was collected and concentrated to give pure 4,4'-diapolycopene-4,4'-dioic acid monomethyl ester (3, $0.9 \mathrm{mg})$.

\subsection{Singlet oxygen quenching activity}

${ }^{1} \mathrm{O}_{2}$ quenching activity was examined by measuring methylene blue-sensitized photooxidation of linoleic acid ${ }^{9)}$. Eighty $\mu \mathrm{L}$ of $0.025 \mathrm{mM}$ methylene blue in $\mathrm{EtOH}$ and $280 \mu \mathrm{L}$ of $100 \mathrm{mM}$ linoleic acid in EtOH with or without $40 \mu \mathrm{L}$ carotenoid $[10 \mu \mathrm{M}, 100 \mu \mathrm{M}$, and $1000 \mu \mathrm{M}$ in EtOH (final concenarion $1 \mu \mathrm{M}, 10 \mu \mathrm{M}$ and $100 \mu \mathrm{M})$ ] were added to micro glass vials $(5.0 \mathrm{~mL})$. The vials were tightly closed with a screw cap and a septum, and the mixtures were illuminated at 7,000 lux at $22^{\circ} \mathrm{C}$ for $3 \mathrm{~h}$ in corrugated cardboard. Then, $100 \mu \mathrm{L}$ of the reaction mixture was removed and diluted to $3.0 \mathrm{~mL}$ with EtOH, and absorbance at $235 \mathrm{~nm}$ was measured to estimate the formation of conjugates dienes ${ }^{10)}$. The value in the absence of carotenoid was determined and ${ }^{1} \mathrm{O}_{2}$ quenching activity was calculated relative to this reference value. Activity is indicated as the $\mathrm{IC}_{50}(\mu \mathrm{M})$ repre- 
Purification of 4, 4'-diapolycopene-4,4'-dioic acid and its antioxidative activity.

senting the concentration at which $50 \%$ inhibition was observed. The $\mathrm{IC}_{50}$ value was calculated by averaging the data from triplicated experiments.

\section{RESULTS}

\subsection{Isolation of pigments}

B. firmus GB1 cells from $10 \mathrm{~L}$ culture were collected by centrifugation, and extracted with $\mathrm{MeOH}$ by sonication. The extracts were partitioned between $n$-hexane/MeOH, and the concentrated $\mathrm{MeOH}$ layer was further partitioned between $t$-buthyl methyl ether-MeOH/ $\mathrm{H}_{2} \mathrm{O}$ without adjusting the $\mathrm{pH}$. The $t$-butyl methyl ether-MeOH layer was evaporated to dryness and purified by subsequent chromatography of HP20SS column chromatography, ODS column HPLC, and polystyrenic column HPLC to give pure 4,4' -diapolycopene-4,4'-dioic acid (1, 1.0 mg).

\subsection{Structural elucidation}

First, 1 was dissolved in $\mathrm{MeOH}$ and analyzed by HRAPCIMS and HRESI-MS in positive and negative modes, and the peak due to molecular ion was not observed in any experiment. The ${ }^{1} \mathrm{H}$ NMR and ${ }^{1} \mathrm{H}-{ }^{1} \mathrm{H}$ DQF COSY analyses of 1 in $\mathrm{CDCl}_{3}-\mathrm{CD}_{3} \mathrm{OD}(2: 1)$ revealed 6 methyl singlet signals $(\delta$ 1.97-2.00) characteristic of acyclic carotenoid, and 2 downfield shifted $s p^{2}$ methine signals ( $\left.\delta 7.34\right)$, suggesting that are located at $\beta$ position of carbonyl functions. The signals due to glycosyl units were not observed in the ${ }^{1} \mathrm{H}$ NMR spectrum. Considering these observations and the high polarity of 1, 1 was proposed to be an acyclic carotenoid possessing carboxylic acid functions.

Since the ${ }^{1} \mathrm{H}$ NMR signals of 1 were very broad, methylation of 1 by diazomethane was performed for further structural analyses. From the $\mathrm{MeOH}$ extract of $17 \mathrm{~L}$ culture of GB1 cells, pure dimethyl ester (2, 2.6 mg) and monomethyl ester (3, $0.9 \mathrm{mg}$ ) were obtained by EtOAc extraction, HW40 column chromatography, and silica gel column chromatography.

Compound 2 was dissolved in $\mathrm{MeOH}$ and analyzed by positive ion HRESI-MS. The $(\mathrm{M}+\mathrm{Na})^{+}$peak was observed at $\mathrm{m} / \approx 511.28400$ [calcd. for $511.28243\left(\mathrm{C}_{32} \mathrm{H}_{40} \mathrm{O}_{4} \mathrm{Na}\right)$ ], and the molecular formula of 2 was determined to be $\mathrm{C}_{32} \mathrm{H}_{40} \mathrm{O}_{4}$ $\left[1\left(\mathrm{C}_{30} \mathrm{H}_{36} \mathrm{O}_{4}\right)+28\left\{\left(\mathrm{CH}_{3}-\mathrm{H}\right) \times 2\right\}\right]$. The ${ }^{1} \mathrm{H}$ NMR spectrum of 2 in $\mathrm{CDCl}_{3}$ gave sharp signals and clearly showed 6 singlet methyl groups attached at the olefin structure $(\delta$ $2.00 \times 4, \delta 2.02 \times 2), 2$ methoxy methyl $(\delta 3.77 \times 2), 14 s p^{2}$ methine $(\delta 6.32-6.67)$, and $2 s p^{2}$ methines groups $\{\delta 7.30$ $(\mathrm{H}-6) \times 2\}($ Table 1$)$. These ${ }^{1} \mathrm{H}$ NMR signals showed good agreement with those of 4,4'-diapolycopene-4,4'-dioic acid dimethyl ester, which were partially reported in the previous report ${ }^{8)}$. The ${ }^{13} \mathrm{C}$ NMR, ${ }^{1} \mathrm{H}-{ }^{1} \mathrm{H}$ DQF COSY, HMQC and HMBC analyses of 2 also confirmed that 2 was 4,4'-diapolycopene-4,4'-dioic acid dimethyl ester. The key long-range couplings observed in the HMBC experiment on 2 are shown in Fig. 1, and the ${ }^{1} \mathrm{H}$ and ${ }^{13} \mathrm{C}$ NMR data for 2, which have not been reported previously are listed in Table 1.

Compound 3 was dissolved in $\mathrm{MeOH}$ and analyzed by negative ion HRESI-MS, and the (M-Na) ${ }^{-}$peak was observed at $m / z 473.27143$ [calcd. for $473.26906\left(\mathrm{C}_{31} \mathrm{H}_{37} \mathrm{O}_{4}\right)$ ]. The molecular formula of 3 was determined to be $\mathrm{C}_{32} \mathrm{H}_{40} \mathrm{O}_{4}$ $\left[1\left(\mathrm{C}_{30} \mathrm{H}_{36} \mathrm{O}_{4}\right)+14\left(\mathrm{CH}_{3}-\mathrm{H}\right)\right]$, and 3 was speculated to be 4,4'-diapolycopene-4,4'-dioic acid monomethyl ester. The ${ }^{1} \mathrm{H}$ NMR spectrum of 3 in $\mathrm{CDCl}_{3}$ was quite similar to that of 2 , while the integration value of methoxy signal $(\delta 3.77)$ was reduced by $1 / 2$, and H-6 ( $\delta$ 7.38) and H-6' $(\delta 7.30)$, and H-18 ( $\delta 2.00)$ and H-18' ( $\delta 2.02)$ in 3 were observed at different chemical shifts due to its asymmetric structure. Thus, we determined 3 to be 4,4'-diapolycopene-4,4'-dioic acid monomethyl ester. The key ${ }^{1} \mathrm{H}_{-}{ }^{13} \mathrm{C}$ long-range couplings observed in the HMBC experiment on $\mathbf{3}$ are shown in Fig. 1, and the ${ }^{1} \mathrm{H}$ and ${ }^{13} \mathrm{C}$ NMR data for 3 , which have not been reported previously are listed in Table 1.

Since 2 and 3 were identified as 4,4'-diapolycopene-4,4' -dioic acid dimethyl ester and monomethyl ester, respectively, 1 was determined to be 4,4'-diapolycopene-4,4'-dioic acid. The ${ }^{1} \mathrm{H}$ data for 1 , which have not been reported previously, are listed in Table 1.

\subsection{Singlet oxygen quenching activity of carotenoids}

We examined the ${ }^{1} \mathrm{O}_{2}$ quenching activity of astaxanthin, which was reported to possess potent activity ${ }^{11)}$, as a positive control. The $\mathrm{IC}_{50}$ value of astaxanthin was $9.3 \mu \mathrm{M}$. The ${ }^{1} \mathrm{O}_{2}$ quenching activity of 1,2 and 3 was evaluated, and their $\mathrm{IC}_{50}$ values were $5.8 \mu \mathrm{M}, 6.2 \mu \mathrm{M}$ and $6.0 \mu \mathrm{M}$, respectively.

\section{DISCUSSION}

In this study, 4,4'-diapolycopene-4,4'-dioic acid(1) could be successfully isolated and the ${ }^{1} \mathrm{H}$ and/or ${ }^{13} \mathrm{C}$ NMR signals of 1, 4,4'-diapolycopene-4,4'-dioic acid dimethyl ester(2) and monomethyl ester $(3)$ were assigned for the first time. As 1 and its related compounds [norbixin (6,6'-diapolycopene- $6,6^{\prime}$-dioic acid ${ }^{12)}$ and $\operatorname{crocetin}\left(8,{ }^{\prime}\right.$-diapolycopene-8,8'-dioic acid $\left.{ }^{13)}\right]$ from the producing plants were not isolated in previous studies successfully, all these compounds may show inconsistent retention behaviors on silica gel and ODS chromatography. We succeeded in purifying 1 by using polystyrenic synthetic adsorbents, named HP20SS, and a CHP20/C10 packed column(both Mitsubishi Chemical Co.) for separation. These resins adsorb compounds by hydrophobic interaction between the compounds and the planar surface of the aromatic-based polystyrene materials, and the surface of the polystyrenic synthetic adsorbents is different from that of silica gel and ODS materials. Since 1 possesses linear and planar struc- 
Table $1{ }^{1} \mathrm{H}$ NMR Data for 4,4'-diapolycopene dioic acid (1) in $\mathrm{CDCl}_{3}-\mathrm{CD}_{3} \mathrm{OD}(2: 1)$, and ${ }^{1} \mathrm{H}$ and ${ }^{13} \mathrm{C}$ NMR Data for 4,4'-diapolycopene dioic acid dimethyl ester (2) and 4,4'-diapolycopene dioic acid monomethyl ester (3) in $\mathrm{CDCl}_{3}$.

\begin{tabular}{|c|c|c|c|c|c|}
\hline & 1 & 2 & & 3 & \\
\hline Position & $\delta_{\mathrm{H}}$ & $\delta_{\mathrm{H}}($ multi, $J(\mathrm{~Hz}))$ & $\delta_{\mathrm{C}}$ & $\delta_{\mathrm{H}}($ multi, $J(\mathrm{~Hz}))$ & $\delta_{\mathrm{C}}$ \\
\hline 4 & & & 169.1 & & 164.1 \\
\hline$-\mathrm{O}-\mathrm{CH}_{3}$ & & $3.77(\mathrm{~s}, 3 \mathrm{H})$ & 51.6 & & \\
\hline 5 & & & 125.5 & & 124.3 \\
\hline 6 & $7.34(\mathrm{~d}, 11.0)$ & $7.30(\mathrm{~d}, 11.9)$ & 138.9 & $7.38(\mathrm{~d}, 11.2)$ & 140.9 \\
\hline 7 & $6.4-6.6$ & $6.51(\mathrm{dd}, 11.9,15.5)$ & 122.9 & $6.54(\mathrm{dd}, 11.2,15.8)$ & 122.7 \\
\hline 8 & $6.6-6.8$ & $6.62(\mathrm{~d}, 15.5)$ & 146.7 & $6.68(\mathrm{~d}, 15.8)$ & 144.3 \\
\hline 9 & & & 135.3 & & 135.2 \\
\hline 10 & $6.3-6.4$ & $6.37(\mathrm{~d}, 11.0)$ & 136.9 & $6.38(\mathrm{~d}, 11.2)$ & 136.0 \\
\hline 11 & $6.6-6.8$ & $6.65(\mathrm{dd}, 11.0,15.0)$ & 124.7 & $6.64(\mathrm{dd}, 11.2,15.2)$ & 124.7 \\
\hline 12 & $6.4-6.6$ & $6.44(\mathrm{~d}, 15.0)$ & 139.7 & $6.43(\mathrm{~d}, 15.2)$ & 140.0 \\
\hline 13 & & & 135.6 & & 135.2 \\
\hline 14 & $6.3-6.4$ & $6.32(\mathrm{~d}, 11.0)$ & 133.7 & $6.32(\mathrm{~d}, 11.0)$ & 134.1 \\
\hline 15 & $6.6-6.8$ & $6.67(\mathrm{dd}, 11.0,15.0)$ & 130.6 & $6.67(\mathrm{dd}, 11.0,15.5)$ & 130.7 \\
\hline 18 & $1.97-2.00$ & $2.02(\mathrm{~s}, 3 \mathrm{H})$ & 12.7 & $2.00(\mathrm{~s}, 3 \mathrm{H})$ & 12.8 \\
\hline 19 & $1.97-2.00$ & $2.00(\mathrm{~s}, 3 \mathrm{H})$ & 12.7 & $2.00(\mathrm{~s}, 3 \mathrm{H})$ & 12.8 \\
\hline 20 & $1.97-2.00$ & $2.00(\mathrm{~s}, 3 \mathrm{H})$ & 12.7 & $2.00(\mathrm{~s}, 3 \mathrm{H})$ & 12.9 \\
\hline $4^{\prime}$ & & & 169.1 & & 168.3 \\
\hline$-\mathrm{O}-\mathrm{CH}_{3}$ & & $3.77(\mathrm{~s}, 3 \mathrm{H})$ & 51.6 & $3.77(\mathrm{~s}, 3 \mathrm{H})$ & 51.6 \\
\hline $5^{\prime}$ & & & 125.5 & & 124.0 \\
\hline 6 & $7.34(\mathrm{~d}, 11.0)$ & $7.30(\mathrm{~d}, 11.9)$ & 138.9 & $7.30(\mathrm{~d}, 11.9)$ & 138.7 \\
\hline $7^{\prime}$ & $6.4-6.6$ & $6.51(\mathrm{dd}, 11.9,15.5)$ & 122.9 & $6.51(\mathrm{dd}, 11.9,15.8)$ & 122.9 \\
\hline $8^{\prime}$ & $6.6-6.8$ & $6.62(\mathrm{~d}, 15.5)$ & 146.7 & $6.61(\mathrm{~d}, 15.8)$ & 144.4 \\
\hline $9^{\prime}$ & & & 135.3 & & 135.2 \\
\hline $10^{\prime}$ & $6.3-6.4$ & $6.37(\mathrm{~d}, 11.0)$ & 136.9 & $6.38(\mathrm{~d}, 11.2)$ & 136.0 \\
\hline $11^{\prime}$ & $6.6-6.8$ & $6.65(\mathrm{dd}, 11.0,15.0)$ & 124.7 & $6.64(\mathrm{dd}, 11.2,15.2)$ & 124.7 \\
\hline $12^{\prime}$ & $6.4-6.6$ & $6.44(\mathrm{~d}, 15.0)$ & 139.7 & $6.43(\mathrm{~d}, 15.2)$ & 140.0 \\
\hline $13^{\prime}$ & & & 135.6 & & 135.2 \\
\hline $14^{\prime}$ & $6.3-6.4$ & $6.32(\mathrm{~d}, 11.0)$ & 133.7 & $6.32(\mathrm{~d}, 11.0)$ & 134.1 \\
\hline $15^{\prime}$ & $6.6-6.8$ & $6.67(\mathrm{dd}, 11.0,15.0)$ & 130.6 & $6.67(\mathrm{dd}, 11.0,15.5)$ & 130.7 \\
\hline $18^{\prime}$ & $1.97-2.00$ & $2.02(\mathrm{~s}, 3 \mathrm{H})$ & 12.7 & $2.02(\mathrm{~s}, 3 \mathrm{H})$ & 12.7 \\
\hline $19^{\prime}$ & $1.97-2.00$ & $2.00(\mathrm{~s}, 3 \mathrm{H})$ & 12.7 & $2.00(\mathrm{~s}, 3 \mathrm{H})$ & 12.7 \\
\hline $20^{\prime}$ & $1.97-2.00$ & $2.00(\mathrm{~s}, 3 \mathrm{H})$ & 12.7 & $2.00(\mathrm{~s}, 3 \mathrm{H})$ & 12.7 \\
\hline
\end{tabular}

tures, hydrophobic interactions between 1 and the polystyrenic synthetic adsorbent will be strong. Furthermore, 1 has many conjugated double bonds that can create $\pi$ interactions with polystyrenic synthetic adsorbents. Strong and consistent retentivity of 1 on polystyrenic synthetic adsorbents may be attributed to the structural and $\pi$ interaction effects mentioned above.
In the ${ }^{1} \mathrm{O}_{2}$ quenching experiments (methylene-blue method), 1, 2 and 3 showed potent antioxidative activities $\left(\mathrm{IC}_{50} 5.8 \mu \mathrm{M}, 6.2 \mu \mathrm{M}\right.$ and $6.0 \mu \mathrm{M}$, respectively) as astaxanthin $(9.3 \mu \mathrm{M})$. Shimidzu et al. reported that an increased number of $\mathrm{C}=\mathrm{C}$ conjugated double bonds and the presence of a $\mathrm{C}=\mathrm{O}$ unit enhance ${ }^{1} \mathrm{O}_{2}$ quenching activity ${ }^{14)}$. In addition, it has been reported that both acyclic carotenoid 


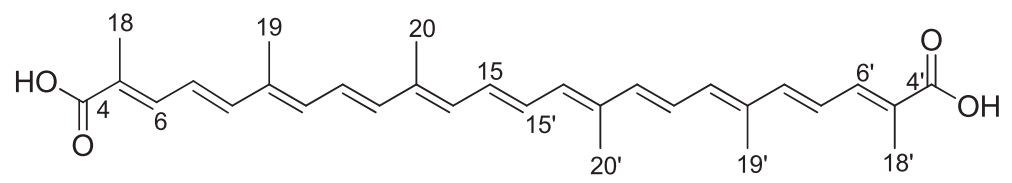

4,4'-diapolycopene dioic acid (1)

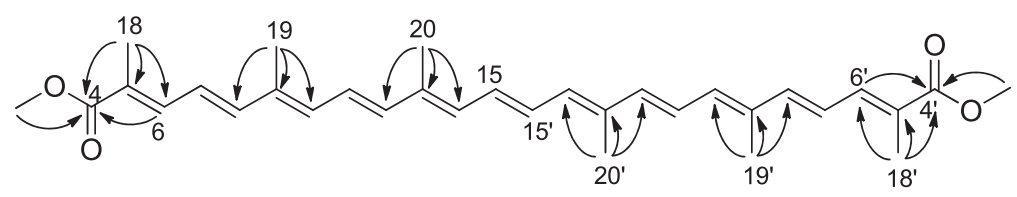

4,4'-diapolycopene dioic acid dimethyl ester (2)

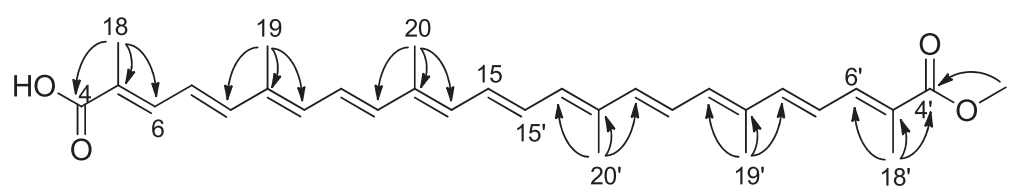

4,4'-diapolycopene dioic acid monomethyl ester (3)

$\longrightarrow{ }^{1} \mathrm{H}_{-}{ }^{13} \mathrm{C}$ long range coupling

Fig. 1 The structure of 4,4'-diapolycopene dioic acid (1), its dimethyl ester (2) and monomethyl ester (3) . The ${ }^{1} \mathrm{H}^{13}{ }^{13} \mathrm{C}$ key long-range couplings of $\mathbf{2}$ and $\mathbf{3}$ are shown as arrows.

and cyclic carotenoid possessing the same number of conjugated double bonds showed the same potent activity ${ }^{15,16)}$. Therefore, the almost identical activities of 1, 2, 3 and astaxanthin may be explainable by their same $\mathrm{C}=\mathrm{C}$ conjugated double bond numbers and $\mathrm{C}=\mathrm{O}$ units. In addition, the almost identical activities of 1, 2, 3 may show that carboxylic and ester functions do not affect ${ }^{1} \mathrm{O}_{2}$ quenching activity.

\section{ACKNOWLEDGMENTS}

We thank Ms. Asami Kasahara, Ms. Shoko Matsuoka, Ms. Kei Ito, Ms. Ai Uchiyama and Ms. Mai Suzuki for their assistance in experiments. We also thank Dr. Takashi Maoka (Research Institute for Production Development) and Dr. Tadashi Adachi(Mitsubishi Chemical Corporation) for the helpful suggestions on the purification of carotenoids.

\section{References}

1) Britton, G.; Liaan-Jensen, S.; Pfander, H. Carotenoid Handbook, Birkhauser Verlag, Basel (2004).

2) Nishino, H.; Tokuda, H.; Murakoshi, M.; Satomi, Y.; Masuda, M.; Onozuka, M.; Yamaguchi, S.; Takayasu, J.; Tsuruta, J.; Okuda, M.; Khachik, F.; Narisawa, T.; Taka- suka, N.; Yano, M. Cancer prevention by natural carotenoids. Biofactors 13, 89-94(2000).

3) Iwamoto, T.; Hosoda, K.; Hirano, R.; Kurata, H.; Matsumoto, A.; Miki, W.; Kamiyama, M.; Itakura, H.; Yamamoto, S.; Kondo, K. Inhibition of low-density lipoprotein oxidation by astaxanthin. J. Atheroscler. Thromb. 7, 216-222(2000).

4) Naito, Y.; Uchiyama, K.; Aoi, W.; Hasegawa, G.; Nakamura, N.; Yoshida, N.; Maoka, T.; Takahashi, J.; Yoshikawa, T. Prevention of diabetic nephropathy by treatment with astaxanthin in diabetic $\mathrm{db} / \mathrm{db}$ mice. Biofactors 20, 49-59 (2004).

5) Hosokawa, M.; Kudo, M.; Maeda, H.; Kohno, H.; Tanaka, T.; Miyashita, K. Fucoxanthin induces apoptosis and enhances the antiproliferative effect of the PPAR gamma ligand, troglitazone, on colon cancer cells. Biochim. Biophys. Acta. 1675, 113-110(2004).

6) Hong, H. A.; Khaneja, R.; Tam, N. M.; Cazzato, A.; Tan, S.; Urdaci, M.; Brisson, A.; Gasbarrini, A.; Barnes, I.; Cutting, S. M. Bacillus subtilis isolated from the human gastrointestinal tract. Res Microbiol. 160, 134143(2009).

7) Khaneja, R.; Perez-Fons, L.; Fakhry, S.; Baccigalupi, L.; Steiger, S.; To, E.; Sandmann, G.; Dong, T. C.; Ricca, E.; Fraser, P. D.; Cutting, S.M. Carotenoids found in Bacillus. J. Appl. Microbiol. 108, 1889-1902(2010).

8) Kleing, H.; Schmitt, R.; Meister, W.; Englert, G.; Thom- 
men, $\mathrm{H}$. New $\mathrm{C}_{30}$-carotenoic acid glucosyl Esters from Pseudomonas rhodos. Z. Naturforsch. 34c, 181-185 (1979).

9) Kobayashi, M.; Sakamoto, Y. Singlet oxygen quenching ability of astaxanthin esters from the green alga Haematococcus pluvialis. Biotechnol. Left. 21, 265-269 (1999).

10) Hirayama, O.; Nakamura, K.; Hamada, S.; Kobayashi, Y. Singlet oxygen quenching ability of naturally occurring carotenoids. Lipids 29, 149-150 (1994).

11) Miki, W. Biological functions and activities of animal carotenoids. Pure Appl. Chem. 63, 141-146 (1991).

12) Scotter, M. J.; Thorpe, S. A.; Reynolds, S. L.; Wilson, L. A.; Strutt, P. R.; Characterization of the principal colouring components of annatto using high performance liquid chromatography with photodiode-array detection. Food Addit Contam. 11, 301-315(1994).

13) Pfander, H.; Schurtenberger, H. Biosynthesis of $\mathrm{C}_{20}$-carotenoids in Crocus sativus. Phytochemistry 21, 1039-1042 (1982).

14) Shimidzu, N.; Goto, M; Miki, W. Carotenoids as singlet oxygen quenchers in marine organisms. Fisheries Science 62 (1), 134-137 (1996).

15) DiMascio, P.; Kaiser, S.; Sies, H. Lycopene as the most efficient biological carotenoid singlet oxygen quencher. Arch. Biochem. Biophys. 274 (2), 532-538(1989).

16) Stahl, W.; Sies, H. Lycopene: a biologically important carotenoid for humans? Arch. Biochem. Biophys. 336 (1), 1-9(1996). 